\title{
Método de ensino de software CAD 3D - 0 vídeo como elemento facilitador da aprendizagem.
}

Method of teaching 3D CAD software - Video as a facilitator of learning.

\author{
SILVEIRA NETO, Walter Dutra; Doutor; Universidade do Estado de Santa Catarina \\ walter.silveira@udesc.br \\ SANTOS, Célio Teodorico; Doutor; Universidade do Estado de Santa Catarina \\ celio.teodorico@gmail.com \\ BRANDÃO, Cláudio de São Plácido; Doutor; Universidade do Estado de Santa Catarina \\ cbrandao@terra.com.br
}

\section{Resumo}

O presente artigo demonstra os resultados obtidos a partir de um experimento com um modelo de tutorial direcionado ao ensino de software CAD Tridimensional.

Para o seu desenvolvimento foram identificados elementos tais como texto, vídeo e imagens estáticas, assim como o software que permitiria a criação do tutorial. Para este experimento foi utilizado um grupo de 19(dezenove) estudantes do curso de Bacharelado em Design Industrial, onde realizou-se uma seção em um laboratório de informática, para que o método proposto pudesse ser testado e verificado.

Os dados apresentados discutem quais as necessidades e preferências do usuário no processo de execução da tarefa visando uma maior interatividade entre instrumento e aprendiz, na busca de uma aprendizagem facilitadora.

Palavras Chave: Design instrucional; ensino-aprendizagem; ensino de software CAD 3D.

\begin{abstract}
The present paper demonstrates the results obtained from an experimental section of a tutorial model directed to the teaching of 3D CAD software.

For its development, elements such as text, video and still images were identified, as well as the software that would allow the creation of the tutorial. For this experiment, a group of 19 (nineteen) students of the Bachelor's degree in Industrial Design was used, where a section was held in a computer lab, so that the proposed method could be tested and verified.

The presented data discusses the needs and preferences of the user in the process of executing the task aiming at a greater interactivity between instrument and apprentice, in the search for a facilitating learning.
\end{abstract}

Keywords: Instructional Design; teaching-learning; teaching 3D CAD software. 


\section{Introdução}

Para quem decide trabalhar com educação, deve fazer porque ama o que faz, assim como qualquer profissão que a vida nos vai direcionando, mas educar e/ou transmitir o saber, não é uma tarefa fácil, pois exige, além do domínio do conteúdo que se deseja emitir, desenvolver algo que facilite o processo de entendimento do conteúdo que será trabalhado, ou seja, criar maneiras que o conteúdo transmitido seja melhor "absorvido" pelo receptor. O objetivo deste texto é demonstrar um método que vem sendo utilizado e otimizado, no sentido de melhor instruir, a fim de facilitar o ensino de software gráficos.

O modelo deste método vem sendo trabalhado, e teve o seu marco inicial com uma dificuldade real na aprendizagem de determinados software que partiam, muitas vezes, de interfaces mal desenhadas ou mal organizadas, dificultando o processo de sua aprendizagem, de qualquer forma vale ressaltar que este texto não irá entrar em detalhes de analisar interfaces de software, mas sim demonstrar formas de facilitar o processo de aprendizagem de software gráficos, e produzir material instrucional para os cursos de design no contexto acadêmico.

Esta pesquisa teve um maior aprofundamento a partir da tese de doutorado, Silveira Neto (2010) "Proposta de Método para Criação e Validação de tutoriais - Aprendizagem de Software Gráfico", onde foram feitos testes com acadêmicos de Design que estudavam e/ou utilizavam software gráfico no desenvolvimento de seus trabalhos, onde, estas avaliações permitiram a coleta de dados fundamentais para o desenvolvimento e aprimoramento de métodos que facilitariam o processo de aprendizagem. Neste estudo foram verificadas diversas ferramentas de ensino, disponibilizadas atualmente nas novas tecnologias da informação, que poderiam ser aplicadas em modalidades de ensino presenciais, semipresenciais e a distância.

\section{Educação presencial, semipresencial e a distância.}

A pretensão aqui não é definir o que já está definido, mas trazer um breve panorama destas três modalidades de ensino, aproximando-as com a realidade atual.

Lidamos com novas tecnologias que fazem com que o ensino obrigatoriamente tende a ser diferenciado, provocado pela realidade que se apresenta, lidamos com um público diferenciado, pessoas conectadas através de redes virtuais, ligadas em redes, grupos, etc., diferente de gerações anteriores, onde não havia a disponibilidade de tanto recursos que temos atualmente, a internet chegou praticamente em cada canto da terra, embora o termo seja forte, não se pode fingir que isto não esteja acontecendo, e se observamos o ensino atual, podemos identificar que ainda utiliza-se métodos idênticos a poucos anos atrás, portanto, sim, temos que nos adaptarmos as novas tecnologias e as novas gerações, caso contrário, iremos de encontro aos nossos receptores, aprendizes, alunos, criando assim uma "turbulência" no processo de emissão/recepção do conhecimento.

\footnotetext{
“Educar é colaborar para que professores e alunos - nas escolas e organizações transformem suas vidas em processos permanentes de aprendizagem. É ajudar os alunos na construção da sua identidade, do seu caminho pessoal e profissional - do seu projeto de vida, no desenvolvimento das habilidades de compreensão, emoção e comunicação que thes permitam encontrar seus espaços pessoais, sociais e profissionais e tornar-se cidadãos realizados e produtivos." (Moran, 2000, p. 137).
} 
Seguindo o raciocínio de Moran, pois, se desejamos durante o processo de aprendizagem auxiliar nossos alunos na construção de suas vidas profissionais, devemos então falar, ou pelo menos, aproximarmo-nos, como transmissores do conhecimento, de linguagens/ferramentas tecnológicas atuais, abrindo assim um canal facilitador entre emissor e receptor.

Retomando a questão das tecnologias informacionais, que atualmente disponibilizamos, a internet vem fazendo com que a maneira de pensar no ensino e na forma que este ensino deverá chegar até seu receptor venha sendo modificada, isto falando, tanto na modalidade presencial e não presencial, devemos nos aproximar a estas linguagens disponíveis e modernizarmos nossos métodos de ensino, pois se temos um conteúdo que basta disponibilizá-lo virtualmente e depois solicitar aos alunos que devolvam o entendimento deste conteúdo, então ele não precisa ser trabalhado em sala (no sentido de estarmos juntos fisicamente), pois não haveria necessidade.

Para o ensino presencial os conteúdos que são trabalhados devem ser repensados, na maneira de como eles serão apresentados, e, que estes sejam valiosos para ambas as partes, pois se esse "encontro" entre emissor (professor) e receptor (aluno) não traga algo significativo, ou seja, quando a aprendizagem acontece melhor quando fazemos pesquisas isoladas do que quando estamos juntos, então não tem sentido que este conteúdo seja trabalhado de forma presencial. Moran et al. (2003).

De forma sucinta, fazendo um apanhado de conceitos/definições referentes a Educação Presencial, pode-se afirmar que ela objetiva de uma construção do conteúdo trabalhado de forma equilibrada entre o indivíduo e o grupo, entre o professor/emissor/facilitador do conteúdo que será transmitido e o receptor/aluno, entendemos que este é um participante ativo neste processo.

O professor, assim como nas demais modalidades de ensino deve ser motivador, expondo os conteúdos, facilitando a sua compreensão, entende-se que neste processo, o professor deverá auxiliar gradativamente o que é transmitido, incentivando e buscando os alunos a terem uma participação mais ativa, no sentido de colaborar com a troca de experiências e compreensões do que é trabalhado. Nesta modalidade, estamos presentes no tempo e espaço, há uma supervisão mais próxima do público receptor, se conhece melhor este público.

$\mathrm{Na}$ educação Semipresencial, analisando-a na forma que compreendemos, ou seja, na visão que temos como experiência de docência, ela aproxima-se da Educação Presencial, mas tem um caráter particular que consideramos muito relevante, onde, além de se ter encontros presenciais, conforme definidos anteriormente na Educação Presencial, assim que o professor entende que determinados conteúdos trabalhados de forma presencial, debatidos em sala e "compreendidos" pelos alunos, esses conteúdos podem ser testados de maneira virtual, ou seja, não presencial, a fim de verificar se o mesmo realmente foi compreendido, ou se houveram pontos aonde a informação chegou de forma incompleta ao seu receptor, para que assim esses pontos possam ser novamente discutidos, e, se tenha um aprendizado satisfatório da aprendizagem.

Segundo Prado e Valente, (2002, p. 31):

“(...) o processo de achar e corrigir o erro constitui uma oportunidade única para o aprendiz aprender sobre um determinado conceito envolvido na solução do problema ou sobre estratégias de resolução de problemas."

Desta forma, a modalidade Semipresencial nos permite, na figura de professor/transmissor 
do conhecimento, testarmos conteúdos que entendemos como mais complexos, e, que estes possam ser trabalhados sem a presença física do professor, pois como comentado por Prado e Valente, se propõe ao aluno o aprenda-a-aprender, identificando suas dificuldades e de que forma elas poderão ser resolvidas. Este é o ponto fundamental desta modalidade e o que a torna, na nossa visão, a mais relevante na obtenção de bons resultados de aprendizagem, pois a figura do professor está presente na maioria dos encontros e ela é determinante para a compreensão de determinados conteúdos mais complexos, facilitando o processo da aprendizagem.

A Educação a Distância (EAD), a qual já funciona no Brasil há décadas, tendo seus primórdios através de cursos por correspondência, como os do Instituto Universal Brasileiro, e posteriormente pela televisão, como o Telecurso 2ㅇ Grau, criado pela Rede Globo. A maior novidade dos últimos anos é a possibilidade do uso de tecnologias interativas, que permitem a comunicação em tempo real entre instrutores e alunos, tais como as teleconferências e a Internet, que tem se desenvolvido em termos de capilaridade, velocidade e incorporação de recursos multimídia.

Segundo Nunes (s.d.), as primeiras abordagens conceituais qualificavam a educação a distância pelo que ela não era, pois estabeleciam uma comparação imediata da EAD com a educação presencial, também denominada educação convencional, direta ou face-a-face, onde o professor, presente em sala de aula, é a figura central. No Brasil, até hoje, muitos costumam seguir o mesmo caminho, preferindo tratar a EAD a partir da comparação com a modalidade presencial da educação. Este comportamento não é incorreto, mas promove um entendimento parcial do que ela realmente o é, em alguns casos, estabelece termos de comparação pouco científicos. Para examinar o conceito de EAD, referenciamos alguns autores que já empreenderam esta tarefa.

Para Dohmem (1967) apud Nunes (1996), educação a distância (Ferstudium) é uma forma sistematicamente organizada de auto-estudo onde o aluno se instrui a partir do material de estudo que the é apresentado. Seu acompanhamento e supervisão é feito por um grupo de professores, utilizando-se meios de comunicação capazes de vencer longas distâncias. $O$ oposto de EAD é a "educação face-a-face", com contato direto entre professores e estudantes. (Dohmem, 1967 apud Nunes, 1994).

Holmberg (1977) apud Nunes (1996), por seu turno, diz que o termo "educação a distância" refere-se a várias formas de estudo, de vários níveis, que não estão sob a contínua e imediata supervisão de tutores presentes com seus alunos nas salas de leitura ou no mesmo local. A educação a distância se beneficia do planejamento, direção e instrução da organização do ensino (Dohmem, 1967 apud Nunes, 1994).

D. Garrison e D. Shale (1987) dizem que a educação a distância envolve dois caminhos de comunicação entre professor e estudante para propor e facilitar o processo educacional utilizando-se a tecnologia necessária para a mediação entre estes.

Segundo Keegan (1991, p. 38), os elementos centrais dos conceitos de EAD são:

(1) separação física entre professor e aluno, que distingue o EAD do ensino presencial;

(2) influência da organização educacional (planejamento, sistematização, plano, projeto e organização rígida), que a diferencia da educação individual;

(3) uso de meios técnicos de comunicação, usualmente impressos, para unir o professor ao 
aluno e transmitir os conteúdos educativos;

(4) comunicação de mão-dupla, onde o estudante pode beneficiar-se da iniciativa no diálogo;

(5) possibilidade de encontros ocasionais com propósitos didáticos e de socialização;

(6) participação de uma forma industrializada de educação, potencialmente revolucionária.

Como conclusão das três modalidades apresentadas acima, se observa claramente que todas têm suas particularidades e funcionalidades eficientes, mas é clara a diferença entre elas, professor e aluno estarem ou não juntos fisicamente, e a pergunta é: "É possível obter os mesmos resultados da aprendizagem entre as modalidades?". Na nossa visão, como professores da área e pesquisadores, especificamente no que aborda o ensino de software gráficos, diríamos que é muito mais difícil transmitir conhecimentos sem a presença de um professor na maior parte das aulas trabalhadas, pois há experiências vivenciadas de quem transmite o conhecimento que não podem ser trabalhadas na modalidade a Distância, entendendo que na modalidade Semipresencial, trabalha-se o que já foi ensinado, testa-se conteúdo, mede-se a aprendizagem e ensina-se o aluno a aprender-a-aprender, uma vez que o aprendiz, no processo de buscar novas informações, estará exercitando suas habilidades de aprender; poderá levantar questões sobre o pensar-sobre-o-pensar, podendo ainda analisar conceitos em termos da efetividade das ideias, estratégias e estilo de resolução de problema, ligadas ao desenvolvimento do conteúdo proposto, relacionado com sua aprendizagem.

\section{0 experimento prático do conteúdo trabalhado - Modelo do tutorial aplicado.}

Neste trabalho foram aplicados dois modelos de tutoriais para que fosse possível testar e obter resultados da eficiência do modelo proposto, para Valente (1993), os tutoriais enquanto modalidade de software educativo, caracterizam-se como uma tentativa de computadorizar o ensino tradicional, tendo o efeito facilitador no processo de aprendizagem. $O$ tutorial em sua essência possuir diversos elementos que fazem com que aconteçam conversas entre seus usuários. Esses elementos nascem da união entre imagens estáticas e dinâmicas, som e mesmo da interligação da informação numa sequência não linear, implementando assim, o conceito de multimídia ou de hipermídia. Por esta razão, os tutoriais são comprovadamente ferramentas muito importantes no processo de ensino/aprendizagem.

Para o modelo construído foram considerados alguns elementos fundamentais para a construção do tutorial, que são:

- Texto - possui um papel essencial dentro de um tutorial e permite a comunicação entre o professor e o aluno. O uso adequado do texto é um importante recurso instrucional. $O$ texto facilita o registro e orienta de forma precisa os passos a seguir e o lugar onde se deseja chegar. De certa forma, através do texto é possível atrair a atenção do usuário.

No tocante à forma visual do texto, pode-se dizer que dentro de um sistema tutorial não existe uma fonte tipográfica que seja boa ou ruim, mas sim fontes apropriadas ou não. Alguns cuidados podem contribuir para que os textos digitais ofereçam melhor 
legibilidade, entre os quais se pode relacionar: o emprego de fontes sem serifa ${ }^{1}$, o tamanho mínimo de 12 pontos para as fontes, a utilização de letras maiúsculas e minúsculas na composição das frases e a adoção de espaçamento duplo para os parágrafos.

Um texto apresentado no corpo de um tutorial pode funcionar como um hipertexto, principal característica da hipermídia, ao permitir ao usuário rapidez de acesso a conteúdos disponibilizados através de seus links. Este conteúdo pode ter diversas formas, como por exemplo: imagem, som, animação etc., que podem ser considerados como documentos "vivos" que ficam armazenados nas diversas páginas e sites disponibilizados na internet. Segundo Lévy (1993) o vocábulo texto já traz em sua estrutura a ideia de hipertexto, uma vez que texto remete a técnica de tecelagem, uma trama realizada entre verbos, nomes, adjetivos e substantivos.

- Imagem estática - as imagens estáticas estão presentes no tutorial para apresentar ao usuário passos e ações que, de certa forma, não se consegue apresentar muito claramente apenas com a utilização do texto escrito. Sendo assim, as imagens estáticas contribuem tanto ao usuário quanto ao desenvolvedor do tutorial, pois elas permitem uma melhor comunicação e ajuda a aumentar a compreensão entre o sistema de tutoria e o público alvo que se deseja atingir, permitindo que a mensagem do professor ou o tutor desejam passar se torne compreensível.

As imagens aqui tratadas são puramente digitais, pois são advindas e/ou geradas por dispositivos que as transformam para o ambiente digital, seja por captura, escaneamento ou criadas diretamente no computador. Após a obtenção destas imagens, deve-se ter um cuidado muito especial com os tipos de arquivos que serão disponibilizados no tutorial, pois, dependendo do compactador utilizado podem-se obter resultados indesejáveis, como por exemplo, tamanho excessivo do arquivo, resultando em muita demora na visualização do tutorial, ou arquivo muito pequeno com perda de resolução, o que ocasionaria em uma imagem desfocada e/ou ilegível.

Dentre os arquivos compactados utilizados e considerando o fato de que o tutorial proposto estará inserido em um AVA e consequentemente disponibilizado na internet, os mais utilizados e que apresentam melhores resultados após sua compactação são os formatos GIF (Formato de Intercâmbio de Arquivo) e o JPEG ${ }^{2}$ (Joint Photographic Experts Group), segundo o dicionário DicWeb (2009). O formato GIF possui uma compactação máxima de 8 bits $^{3}$ de informações em cores, o que corresponde a 256 cores em pixels ${ }^{4}$ diferentes. Ele é ideal para imagens que contenham áreas de cor lisa

\footnotetext{
${ }^{1} \mathrm{Na}$ tipografia, as serifas são os pequenos traços e prolongamentos que ocorrem no fim das hastes das letras.

2 JPEG (ou JPG) é um método comumente usado para comprimir imagens fotográficas. O grau de redução pode ser ajustado, o que permite a você escolher o tamanho de armazenamento e seu compromisso com a qualidade da imagem. Geralmente se obtém uma compressão com pouco perceptível perda na qualidade da imagem.

${ }^{3}$ Unidade mínima de informação possível de ser interpretada e armazenada pelo computador. Um bit pode assumir, apenas um de dois valores: 1(um) ou 0(zero). Fonte: DicWeb. Disponivel em: http://www.dicweb.com/bb.htm. Acesso: 28/09/2015.

${ }^{4}$ 1- Menor unidade de representação de uma imagem em um monitor. Cada pixel representa uma única cor e da combinação de cada um, é possível visualizar qualquer cor. 2 - Unidade de dimensão de imagem numa página Web, e também o grau de resolução de uma imagem digitalizada. Fonte: DicWeb. Disponivel em:
} 
e borda rígida. Já os arquivos de formato JPEG são constituídos por imagens de cores em 24 bits, podendo conter milhões de cores, sendo um tipo de arquivo ideal para imagens fotográficas e ilustrações digitais realistas. Vale lembrar que para o uso de um dos formatos nos tutoriais não é necessário que sua resolução ultrapasse $72 d p i^{5}$, pois este é o padrão estabelecido para a WEB até este momento.

- Imagem dinâmica - as imagens dinâmicas permitem transmitir mensagens, onde nem mesmo a escrita e/ou as imagens estáticas conseguem comunicar. Ela possibilita ao professor ou tutor demonstrar, através de captura de tela do software ou também por meio de geração através de software específicos de animação, o que deverá ser feito em um determinado passo do tutorial. É um elemento muito importante, mas por tratar-se de arquivos geralmente grandes, em termos de tamanho, deve-se ter muito controle na sua utilização, pois elas podem fazer com que o passo do tutorial onde se faz o uso deste recurso torne-se muito lento para sua visualização. Isso propicia que o usuário o ignore, ocasionando a perda da mensagem que deveria ser transmitida. Além da animação transmitir o que a imagem estática e o texto não consegue fazer, ela desperta a atenção e torna as informações mais claras, o que reforça a importância, em alguns casos, de sua utilização em ícones do tutorial. Contudo, o uso destes deve se dar em casos realmente específicos e com moderação para uma melhor legibilidade, caso contrário o resultado será a presença de telas poluídas visualmente, desviando a atenção do usuário e perdendo seu objetivo maior que é o aprendizado.

Para que se consiga uma boa resolução em vídeos de longa duração ${ }^{6}$, é importante o uso de $\mathrm{CODECs}^{7}$, que podem ser classificados em dois grupos:

a) CODECs sem perdas de qualidade, que codificam som ou imagem para comprimir o arquivo sem alterar as fontes originais. Se o arquivo for descomprimido, o novo arquivo será idêntico ao original. Esse tipo de codec gera arquivos codificados que são entre 2 a 3 vezes menores que os arquivos originais, sendo os mais utilizados: - HuffYUV, que é um codec de vídeo sem perdas criado por Ben Rudiak-Gould.

- H.264, que é um padrão para compressão de vídeo baseado no MPEG-4.

b) CODECs com perda de qualidade, que codificam som ou imagem, gerando certa perda de qualidade com a finalidade de alcançar maiores taxas de compressão. Essa perda de qualidade é balanceada com a taxa de compressão para que não sejam criados artefatos perceptíveis. Por exemplo, se um instrumento muito baixo toca ao mesmo tempo em que outro instrumento mais alto, o primeiro é suprimido, já que dificilmente será ouvido.

Os CODECs de vídeos mais utilizados dentro desta categoria são:

http://www.dicweb.com/pp.htm. Acesso: 28/09/2015.

${ }^{5}$ (Pontos por polegadas). Medida de resolução de uma tela de computador. A qualidade da imagem é diretamente proporcional a quantidade de pontos por polegada. Fonte: DicWeb. Disponivel em: http://www.dicweb.com/dd.htm. Acesso: 28/09/2017.

${ }^{6}$ Para os tutoriais pode-se considerar como vídeos de longa duração, vídeos que duram no máximo 20 min, pois além deste tempo o vídeo ficará monótono e confuso, prejudicando assim a mensagem do que se deseja transmitir.

${ }^{7}$ É o acrônimo de Codificador/Decodificador, dispositivo de hardware ou software que codifica/decodifica sinais. 
- Xvid, que é um software livre e codec de vídeo padrão MPEG-4 de código aberto. Foi criado por um grupo de programadores voluntários depois que o OpenDivx foi fechado em julho de 2001.

- DivX, que foi criado pela DivX, Inc., foi produzido para ser usado em compactação de vídeo digital, deixando os vídeos com boa qualidade apesar da alta compactação. O DivX é compatível com Windows, Linux, Solaris e Mac OS X.

Acima foram descritos os CODECs mais utilizados atualmente, obviamente que alguns foram suprimidos, entendendo que cada um deverá ter uma aplicação específica dependendo de cada caso. A escolha do CODEC deve-se a sua utilização, ou seja, a mídia onde o tutorial será inserido. Os CODECs estão diretamente relacionados aos vídeos, como também nas imagens estáticas, na forma de disponibilizá-las em arquivos menores, ou seja, na codificação que elas deverão possuir, um exemplo de codec utilizado em imagens estáticas são os arquivos no formato “.JPG".

Os tutoriais que foram utilizados neste experimento possuem como objetivo, o uso de ferramentas básicas/intermediárias do software Solidworks, possuindo o intuito de reforçar a sua prática, assim como mostrando técnicas avançadas para a modelagem de objetos em um ambiente tridimensional. A proposta foi modelar duas peças básicas, mas que de certa forma podem ser consideradas um pouco complexas, visto que as técnicas trabalhadas no tutorial permitem que sua modelagem possa ser simplificada, sempre que uma ferramenta ou angulação da vista do objeto torna-se difícil ser mostrada em imagens (prints ${ }^{8}$ de tela), sentiu-se a necessidade de inserir um vídeo demonstrativo para que o aluno possa compreender melhor o comando a ser executado.

Os vídeos facilitam muito o processo de aprendizagem/compreensão por parte do aluno, pois ele pode observar de que forma deverá ser executado o passo do tutorial, na nossa visão como professores e usuários deste método, os vídeos não devem ser muito longos, pois foi verificado na prática que quando existem vídeos longos, o aluno/aprendiz acaba não visualizando o mesmo na íntegra, e, com isso, perde conteúdos importantes que são transmitidos no passo do tutorial onde o vídeo se faz necessário. Infelizmente para este artigo não será possível inserir o tutorial em sua íntegra, ou seja, com seus vídeos incorporados no seu texto, pois isto acarretaria em um arquivo de tamanho significativo, mas de qualquer forma será apresentado abaixo alguns passos do tutorial para que se possa entender melhor o que vem sendo abordado neste trabalho. Também vale ressaltar que as imagens foram reduzidas em seu tamanho, para obedecer a formatação do documento estabelecida para este congresso, portanto elas poderão perder sua legibilidade/clareza, mas de qualquer forma pode-se verificar a estrutura do tutorial utilizado para este experimento.

\section{Modelo do tutorial aplicado}

Desenvolvimento de uma manopla

\footnotetext{
8 Print, ou print screen é um comando usado para capturar em forma de imagem tudo que está presente na tela do computador, (exceto o ponteiro do mouse e vídeos).
} 
Figura 1 - Modelo proposto

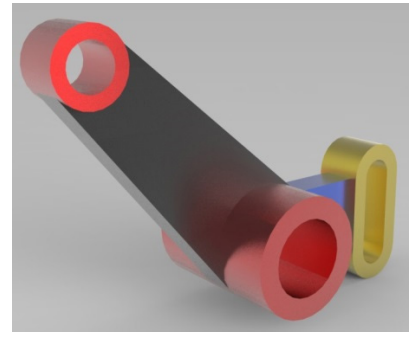

Fonte: Silveira Neto (2017)

Siga as etapas abaixo:

1. Em um mesmo esboço, no plano frontal, faça os desenhos conforme imagem abaixo (a origem será sua referência):

Figura 2 - Vista lateral do modelo a ser construído

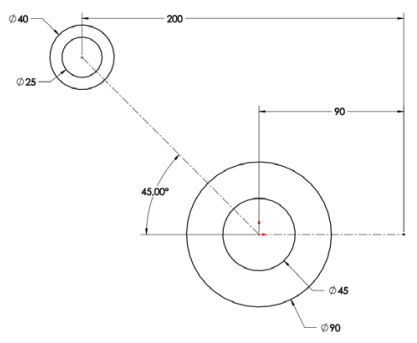

Fonte: Silveira Neto (2017)

2. Agora para posicionarmos os oblongos, faremos os seguintes ajustes:

a. Crie uma relação coincidente entre a extremidade da centerline e o centro dos oblongos;

b. Feito o passo anterior, crie duas linhas horizontais, ligando o oblongo externo com o círculo externo, observe as imagens, abaixo vídeo explicativo:

Figura 3 - Vista lateral do modelo a ser construído, complemento

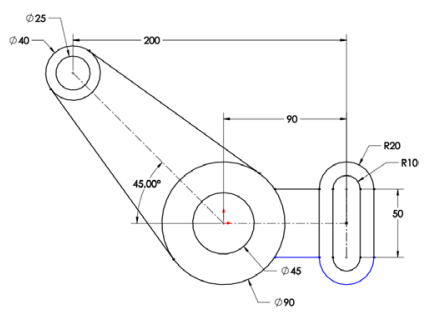

Fonte: Silveira Neto (2017)

Vídeo explicativo... 
3. Adicione mais duas linhas tangentes ao mesmo esboço, caso necessário, crie as relações tangenciais entre a extremidade da linha e o arco do círculo:

Figura 4 - Geração de novo esboço

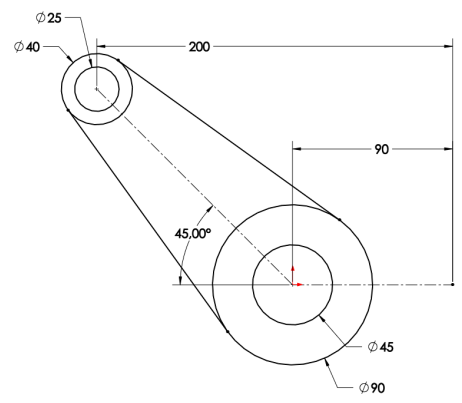

Fonte: Silveira Neto (2017)

4. Ainda no mesmo esboço, criaremos dois oblongos utilizando o comando ranhura reta, observe, depois posicionaremos na sua posição definitiva, na dúvida observe o vídeo demonstrativo:

Figura 5 - Dimensões da ranhura
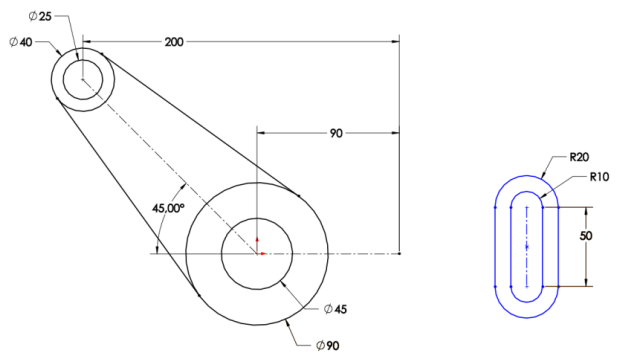

Fonte: Silveira Neto (2017)

5. Agora para posicionarmos os oblongos, faremos os seguintes ajustes:

a. Crie uma relação coincidente entre a extremidade da centerline e o centro dos oblongos;

b. Feito o passo anterior, crie duas linhas horizontais, ligando o oblongo externo com o círculo externo, observe as imagens, abaixo vídeo explicativo: 
Figura 6 - Orientação de construção

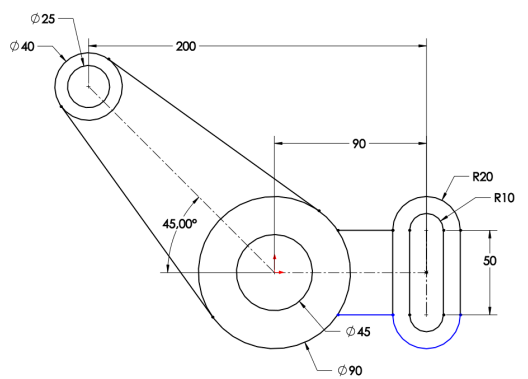

Fonte: Silveira Neto (2017)

Vídeo explicativo...

6. Altere a dimensão do círculo com diâmetro 90 para 70;

Figura 7 - Relação de diâmetros

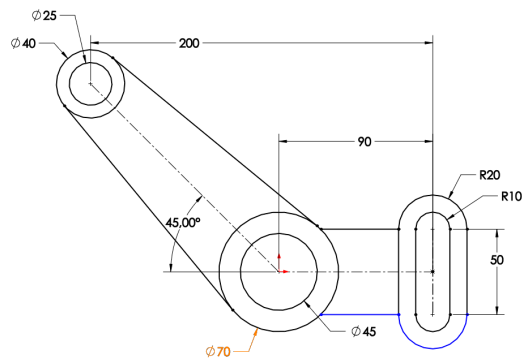

Fonte: Silveira Neto (2017)

7. Agora vamos criar a extrusão de $30 \mathrm{~mm}$ da peça, objetivando esboços previamente selecionados, observe imagem/vídeo abaixo:

Figura 8 - Exemplo de extrusão por seção

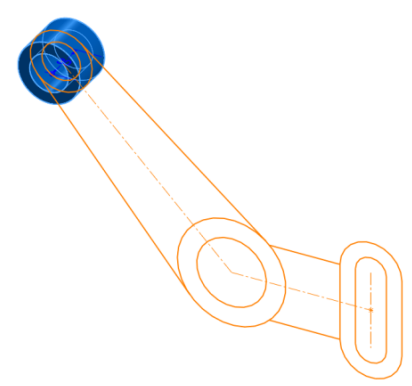

Fonte: Silveira Neto (2017)

Vídeo explicativo...

130 Congresso Brasileiro de Pesquisa e Desenvolvimento em Design, Univille, Joinville (SC)

05 a 08 de novembro de 2018 
8. Agora vamos extrudar as seções seguintes, selecione o esboço que foi utilizado no passo anterior, caso ele não apareça, deixe-o visível, observe vídeo, neste vídeo faremos a sequência de todas as seções, mas lembre-se de que as extrusões devem ser feitas separadamente, pois elas possuem valores distintos:

As seções terão as seguintes cotas:

- seção $2=20 \mathrm{~mm}$, seção $3=90 \mathrm{~mm}$, seção $4=20 \mathrm{~mm}$ e a seção $5=30 \mathrm{~mm}$. Vídeo explicativo...

9. Pronto, sua peça deverá estar assim:

Figura 9 - Resultado esperado do modelo no tutorial aplicado

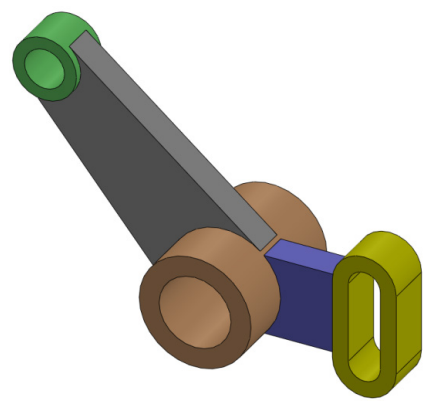

Fonte: Silveira Neto (2017)

Como pode ser observado nos dois tutoriais acima é que ambos não possuem seus vídeos, no ponto onde houve a necessidade de inserção de vídeos os mesmos foram substituídos por um texto destacado "Vídeo explicativo...", isto ocorreu apenas para que a publicação deste texto fosse permitida, caso contrário, teríamos problemas no seu salvamento, não permitindo a incorporação do vídeo em seu conteúdo.

\section{Resultados}

Para que fosse permitido alcançar os resultados, foram feitos testes práticos com uma turma de 19(dezenove) alunos da $5 \underline{a}$ fase do curso de Design, onde se pretendia obter dados que pudessem medir a eficiência do método de tutoria trabalhado, objetivando possíveis melhorias que viessem a contribuir para a construção de novos tutoriais, também através do questionário buscava-se obter informações referentes a aquisição do conhecimento, ou seja, a aprendizagem em si.

Ao final de cada tutorial, os alunos responderam o questionário onde foi possível obter resultados como:

- facilidade de interpretação do conteúdo do tutorial;

- legibilidade e clareza;

- desenvolvimento total ou parcial do conteúdo proposto no tutorial;

- contribuição dos vídeos; 
- contribuição das imagens estáticas;

- utilização de dois monitores ligados em paralelo sendo estes uma com o tutorial, para seu acompanhamento e outro com o tutorial para o desenvolvimento do objeto de estudo;

- validação do modelo proposto;

- melhorias que poderiam ser feitas no conteúdo do tutorial;

De forma resumida, os tópicos descritos acima eram a base de cada resposta que se desejava obter no questionário utilizado com os estudantes.

Na pergunta a qual se desejava identificar a "facilidade de interpretação do conteúdo do tutorial", se observe que foi unânime que as respostas colocando "que a maneira detalhada $e$ sequencial em que o conteúdo foi exposto/colocado, facilita muito a visualização/entendimento de como deverá ser o desenvolvimento do objeto que se está propondo". Assim acontece no quesito "legibilidade e clareza", o qual se pode verificar que grande parte dos estudantes responderam "que as imagens e instruções são suficientemente claras para que se possa entender a construção do objeto proposto, mas salientam que os vídeos se tornam indispensáveis em etapas mais complexas da modelagem".

Em análise do resultado dos objetos modelados "desenvolvimento total ou parcial do conteúdo dos tutoriais", se verificou que nas etapas mais complexas os estudantes recorreram aos vídeos para o seu desenvolvimento, pois os vídeos demonstravam e permitiam a visualização do objeto em diferentes vistas.

Conforme já foi descrito acima, se pode constatar que a "contribuição dos vídeos" se torna indispensáveis em etapas onde a visualização bidimensional não flexibiliza a construção de peças 3D, pois há necessidade de poder visualizar a peça (objeto a ser modelado) em diferentes ângulos, e isto foi verificado com fundamental importância em um processo de modelagem tridimensional.

Em relação a importância da "utilização de laboratórios com computadores conectados a dois monitores", também foi confirmado por todos os estudantes que desta forma, "a aquisição do conhecimento seria mais ágil e facilitada, pois poderíamos visualizar os passos do tutorial em um monitor e no outro estaríamos desenvolvendo/testando a construção dos modelos no software em estudo, assim como os vídeos poderiam ser visualizados, e, em conformidade estaríamos construindo o objeto simultaneamente".

A validação do método aplicado foi confirmada, pelas observações e respostas dos estudantes, em relação ao questionário aplicado, e aos resultados obtidos na prática, sua eficiência se confirmou no desenvolvimento dos exercícios de forma mais intuitiva e rápida, não requerendo a necessidade de consulta a outros materiais, como livros e apostilas, assim como ao professor, essa facilidade de compreensão obedece aos princípios de usabilidade e fatores humanos.

Em relação a melhorias e aperfeiçoamento do método trabalhado, a maioria dos alunos responderam que "a inserção de um número maior de vídeos auxiliaria o processo de construção de objetos tridimensionais em software CAD", também se obteve respostas como "a utilização de dois monitores auxiliaria muito no processo da aprendizagem, pois principalmente nas partes que contém os vídeos, fica muito difícil ficar alternando entre as telas: tutorial e software". 


\section{Conclusões}

Analisando todo o processo, pois como o desenvolvimento desta aplicação em sala foi acompanhado do início ao fim, se pode verificar muitos pontos importantes e significativos.

O primeiro deles, está ligado ao design instrucional que deve ser praticado constantemente na elaboração de material didático, que otimize os processos de ensino aprendizagem na graduação em design, e neste caso, melhorar o desempenho dos alunos na realização de tarefas para construção de artefatos. Aproveitar os recursos tecnológicos e muitas vezes a falta de equipamentos nos laboratórios escolares; o material desenvolvido permite a sua utilização não presencial, ampliando o seu alcance pedagógico.

Outra observação importante refere-se à dificuldade que os estudantes tiveram em construir o modelo proposto no tutorial em um único monitor, ficou evidente a perda de tempo em alternar as telas entre tutorial e software, constatando a importância na aquisição da aprendizagem se o trabalho fosse realizado em dois monitores: um com o tutorial e outro com o software, objeto de estudo, ou com laboratórios equipados com monitores Ultrawide ${ }^{9}$ com um mínimo de 34", pois estes se equivaleriam a aproximadamente dois monitores de 20 ", o que resolveria este quesito da mesma maneira através da divisão de janelas.

Também foi observado que somente as imagens estáticas dificultaram o desenvolvimento do objeto em estudo, a construção de um modelo tridimensional em um software CAD, pois se não houvessem os vídeos, a visualização do modelo, assim como a forma de sua construção, ficaria dificultada, podendo gerar erros no resultado, e, também fazer com que a aquisição do conhecimento ficasse prejudicada, o que invalidaria o método aqui proposto. De qualquer forma, vale ressaltar que as imagens estáticas são de extrema importância, pois elas, além de não fazer com que o arquivo fique muito carregado para sua execução, permite com que se possa demonstrar as telas e posicionamento dos comandos/ferramentas do software, assim como valores/parâmetros utilizados nestas ferramentas, elas também auxiliam quando se deseja mostrar uma vista técnica com a disposição de cotas estabelecidas, o que se pode afirmar que ambos devem ser utilizados neste método, imagens estáticas e dinâmicas, pois estas se complementam.

Em relação a legibilidade e clareza dos tutoriais, temos observado que uma grande maioria de desenvolvedores destes métodos de tutoria falham em classificar seus tutoriais com níveis, como por exemplo: iniciante, intermediário e avançado, consideramos que é difícil poder classificar um tutorial, pois depende muito do aprofundamento que um determinado aprendiz possui, muitas vezes o que é considerado um tutorial iniciante, para uma determinada pessoa que vai utilizar seu tutorial como material de estudo, pode ser intermediário e/ou avançado e viceversa, pois os software CAD 3D, possuem diversos ambientes, por exemplo: modelagem de chapas metálicas, modelagem de sólidos, modelagem por superfície, entre outros., então, podemos nos deparar com um aprendiz que possui total domínio de modelagem de sólido, mas não possui nenhum domínio em uma modelagem por superfície, sendo assim ele é um iniciante se o conteúdo do tutorial trabalhado é sobre modelagem através de superfície. Neste raciocínio, e,

\footnotetext{
${ }^{9}$ Os monitores Ultrawide são monitores que possuem uma taxa de proporção de 21:9 em relação a taxa de 16:9 nos monitores tradicionais, estes monitores possuem um campo de visão expandido em sua largura.
} 
quando se constrói um tutorial, devemos considerar o estudante/aprendiz sempre como iniciante e detalhar o máximo possível todos os passos do tutorial, não omitindo qualquer informação, considerando que o aluno já possa conhece-la, pois isto dificultaria a aprendizagem, ou até mesmo faria com que o aprendiz parasse em uma das etapas, desmotivando-o a continuar, portanto prezamos em detalhar de forma muito minuciosa toda e qualquer etapa/passo do tutorial que se está construindo, partindo sempre do princípio que o aprendiz possa desconhecer uma determinada ferramenta, o método desenvolvido para este estudo considerou isto como um dos quesitos mais importantes, fornecer ao estudante todos os detalhes de cada passo de um tutorial. A elaboração do tutorial considerou o aluno como aprendiz, no caso do experimento, os alunos possuíam um nível intermediário, no entanto, o nivelamento em uma turma passa a ser necessário para equiparar o conhecimento.

\section{Referências bibliográficas.}

KEEGAN, S.D; HOLMBERG B.; MOORE, M,; PETERS, O.; DOHMEM, G. Distance Education International Perspectives. London: Routllege, 1991.

LÉVY, P. As tecnologias da inteligência: o futuro do pensamento na era da informática. Tradução de Carlos Irineu da Costa. São Paulo. Ed. 34, 1993

- O que é o virtual. São Paulo, Ed. 34, 1996.

- A inteligência coletiva: por uma antropologia do ciberespaço. Tradução de Luiz Paulo Rouanet. 5ạ.ed. São Paulo, Loyola, 1998.

- Cibercultura. Tradução de Carlos Irineu da Costa. São Paulo. Ed. 34, 1999

MORAN, José Manuel. Informática na Educação: Teoria \& Prática. Porto Alegre, vol. 3, n.1 (set. 2000) UFRGS. Programa de Pós-Graduação em Informática na Educação, pág. 137-144.

MORAN, José Manuel, MASETTO, Marcos e BEHRENS, Marilda. Novas Tecnologias e Mediação Pedagógica. 7ạ ed. Campinas: Papirus,2003, p.11-65.

NUNES, Ivônio Barros. Noções de educação a distância. 1996. Disponível em: <http://www.ibase.org.br/ined/ivonio1.html>. Acesso em 10 abr. 2008.

PRADO, Maria Elisabette Brisola Brito e Valente, José Armando. In: Educação a distância: fundamentos e práticas. Organizadora Maria Candida Moraes. Campinas - SP, UNICAMP/NIED, 2002.

SILVEIRA NETO, Walter Dutra. Proposta de Método para Criação e Validação de tutoriais Aprendizagem de Software Gráfico. 2010. Disponível em: http://www.lambda.maxwell.ele.pucrio.br/Busca_etds.php?strSecao=resultado\&nrSeq=21631@1. Acesso em 10 set. 2017.

VALENTE, J.A.. Computadores e Conhecimento: Repensando a Educação. Campinas, SP: UNICAMP, 1993.

VALENTE, J. A. (Org.) Por Quê o Computador na Educação? In: Computadores e Conhecimento Repensando a Educação. - Cap. 2 - Campinas, SP, Gráfica Central da UNICAMP, 1993. 